\title{
ANALISIS SALURAN PEMASARAN UBI.JALAR DI DESA.CILEMBU KECAMATAN PAMULIHAN.KABUPATEN SUMEDANG
}

\section{PERFORMANCE OF SWEET POTATO SUPPLY CHAIN IN CILEMBU VILLAGE, PAMULIHAN DISTRICT, SUMEDANG REGENCY}

\author{
Rosida Susanti*, Dini Rochdiani \\ Universitas Padjadjaran Jl. Raya Bandung Sumedang KM. 21 \\ *Email: susantirosida@gmail.com \\ (Diterima 10-1-2021; Disetujui 18-1-2021)
}

\begin{abstract}
ABSTRAK
Salah satu sumber karbohidrat non beras yang bergizi tinggi dan sangat potensial sebagai penunjang pengembangan pangan adalah ubi jalar. Kabupaten Sumedang merupakan salah satu sentra produksi ubi jalar di Indonesia dimana ubi jalar yang paling populer adalah yang berasal dari Desa Cilembu. Penelitian ini bertujuan untuk menganalisis: (1) Saluran dan fungsi pemasaran ubi jalar di Desa Cilembu. (2) Margin pemasaran, farmer's share, dan R/C pemasaran ubi jalar di Desa Cilembu. Pemilihan objek penelitian dilakukan secara sengaja (purposive) dengan pertimbangan bahwa lokasi penelitian merupakan salah satu sentra ubi jalar yang memiliki ciri khas dan berbeda dengan daerah lainnya. Responden dalam penelitian ini adalah 20 petani yang dijadikan bahan untuk memberikan jawaban yang berkaitan dengan penelitian yang diambil secara sengaja (purposive) dan 3 pedagang besar, 3 pedagang kecil, serta 4 orang tengkulak yang diambil secara snowball. Informan yang diambil dalam penelitian ini adalah ketua kelompok tani dan pemilik industri pengolahan ubi jalar. Analisis yang digunakan ialah analisis deskriptif. Hasil penelitian menunjukkan bahwa (1) Terdapat empat saluran pemasaran ubi jalar dari petani sampai ke tangan konsumen akhir dimana terdapat 4 lembaga pemasaran yang terlibat, yaitu tengkulak, pedagang besar, pedagang kecil, dan industri pengolahan. Fungsi pemasaran yang dilakukan petani adalah fungsi pertukaran dan fungsi fasilitas sedangkan fungsi pemasaran yang dilakukan tengkulak, pedagang besar, pedagang kecil, dan industri pengolahan adalah fungsi pertukaran, fungsi fisik, dan fungsi fasilitas. (2) Dilihat dari nilai margin pemasaran, farmer's share, dan nilai R/C saluran pertama, kedua, dan keempat sudah mencapai kinerja yang optimal. Sedangkan pada saluran ketiga, belum mencapai kinerja yang optimal karena memiliki nilai farmer's share yang rendah walaupun nilai margin pemasaran dan $\mathrm{R} / \mathrm{C}$ sudah cukup tinggi.
\end{abstract}

Kata Kunci: farmer's share, margin pemasaran, rasio keuntungan dan biaya, saluran pemasaran, ubi jalar

\section{ABSTRACT}

Sweet potato is a non-rice carbohydrate source that is highly nutritious and has a great potential as a support for food development. Sumedang Regency is one of the centers of sweet potato production in Indonesia, where the most popular sweet potatoes are those from Cilembu Village. This study aims to analyze (1) The channels and functions of sweet potato marketing in Cilembu Village. (2) Marketing margin, farmer's share, and profit ratio and marketing cost of sweet potato in Cilembu Village. The selection of the research object was carried out purposively with the consideration that the research location was one of the sweet potato centers wich had its characteristics and were different from other regions. Respondents in this study were 20 farmers who were used as material to provide answers related to research taken on purpose (purposive) and 3 wholesalers, 3 small traders, and 4 middlemen taken by a snowball. The informants taken in this study were the head of the farmer group and the owner of the sweet potato processing industry. The analysis used in this research is descriptive. The result showed that (1) There were 4 marketing channels for sweet potatoes from farmers to the end consumers where there were 4 


\section{ANALISIS SALURAN PEMASARAN UBI JALAR DI DESA CILEMBU \\ KECAMATAN PAMULIHAN KABUPATEN SUMEDANG \\ Rosida Susanti, Dini Rochdiani}

marketing institutions involved namely middlemen, wholesalers, small traders, and processing industries. The marketing function carried out by farmers in an exchange function and facilitating function, while the marketing function carried out by middlemen, large traders, small traders, and processing industries is an exchange function, a physical function, and a facility function.; (2) Judging from the value of the marketing margin, farmer's share, and the $R / C$ value of th the first, second, and fourth channels have achieved optimal performance. Meanwhile in the third channel, it has not achieved optimal performance because it has a low farmer's share value even though the value of the marketing margin and $R / C$ is quite high.

Keywords: farmer's share, marketing margin, profit ratio and marketing cost, marketing channel, sweet potato

\section{PENDAHULUAN}

Meningkatnya kesadaran masyarakat terhadap pentingnya pakan sehat maka tuntutan konsumen akan bahan pangan juga mulai bergeser. Ubi jalar merupakan salah satu bahan pangan yang diminati dan dicari konsuemen karena tidak hanya memiliki komposisi gizi akan tetapi penampakan dan cita rasanya juga menarik dan mempunyai fungsi fisiologis tertentu bagi tubuh. (Prasetyana, 2010). Selan itu, menurut Zuraida dan Suriati (2005), ubi jalar merupakan salah satu sumber karbohidrat non beras yang bergizi tinggi dan sangat potensial.sebagai penungjang pengembangan pangan.

Ubi jalar dapat menjadi alternatif untuk mendampingi beras dengan alasan bahwa ubi jalar sesuai dengan agroklimat sebagian besar wilayah Indonesia. Produktivitas ubi jalar dinilai tinggi sehingga menguntungkan untuk diusahakan. Ubi jalar juga mengandut zat yang berpengaruh positif terhadap kesehatan, yaitu zat gini. Program diversifikasi pangan dapat dilakukan dengan menggunakan ubi jalar. Menurut Zuraida dan Supriati (2005), kandungan gizi mineral di dalam 100 gram nasi lebih rendah jika dibandingkan dengan mineral yang terkandung pada ubi jalar.

Kabupaten Sumedang telah menjadikan ubi jalarnya tersebut sebagai salah satu produk unggulan pada Pemberdayaan.Produk Unggulan Daerah Kabupaten Sumedang. Menurut Suriawiria, ubi jalar yang paling populer adalah ubi jalar yang berasal dari Desa Cilembu, Kecamatan Pemulihan Kabupaten Sumedang, Jawa Barat.

Ubi jalar di Kabupaten Sumedang banyak dikonsumsi masyarakat dan populer dengan nama ubi cilembu. Ubi Cilembu sangat cocok dengan keadaan lahan di Sumedang yang memiliki tanah yang gembur dan subur. Dinamakan ubi cilembu karena ubi tersebut ditemukan di Desa Cilembu. Ubi cilembu dapat ditanam di sawah maupun lahan kering. 
Ubi cilembu memiliki rasa yang sangat manis dan tekstur yang lait. Menurut Amalia, ubi cilembu dikenal luas di seluruh Indonesia, bahkan sampai diekspor di Jepang, Singapura, Hongkong, dan Malaysia.

Menurut Suismono (2001), ubi cilembu memiliki pangsa pasar yang luas. Kandungan bahan kering yang terdapat pada ubi cilembu relatif lebih tinggi jika dibandingkan dengan ubi jalar lainnya. Menurut Hidayat dkk (2017), kurangnya infomasi yang cukup mengenai kualitas yang dibutuhkan pasar sehingga menyebabkan pedagang besar kesulitan untuk memenuhi jumlah pasokan yang dibutuhkan pasar. Produksi ubi jalar Desa Cilembu tidak terlepas dari keterikatan antara sektor pertanian dari hulu sampai hilir.

Harga yang fluktuatif dan tidak sebanding dengan kenaikan harga input menjadi kendala yang paling banyak dikeluhkan petani. Selain itu, adanya gabungan kelompok tani juga belum begitu terlihat perannya.bagi petani..yang mengusahakan..ubi jalar, karena bantuan dari pemerintah kepada kelompok tani yang paling banyak adalah untuk komoditas tani yang paling banyak adalah untuk komoditas padi seperti bantuan benih unggul. Saluran pemasaran perlu ditinjau untuk mengetahui pola saluran pemasaran ubi jalar di Desa Cilembu dan juga melihat saluran mana yang lebih efisien.

Kotler (2005) menyatakan bahwa pemasaran merupakan proses sosial dan manajerial dari satu individu atau pun kelompok yang tujuannya untuk memenuhi kebutuhan dan keinginan yang..dilakukan..melalui..penciptaan.

Pemasaran sendiri memegang peran yang penting dalam suatu sistem agribisnis dimana pemasaran akan menciptakan.nilai

tambah..serta..membentuk mata rantai distribusi produk yang menghubungkan antara petani dengan konsumen akhir selain fungsinya menentukan keberhasilan suatu kegiatan bisnis. Dalam proses pemasaran terdapat lembagalembaga pemasaran yang dimulai dari produsen sampai ke konsumen yang terlibat dalam saluran pemasaran sehingga biasanya terjadi perbedaan harga yang diterima produsen dengan harga yang dibayar konsumen. Adanya biaya dan keuntungan pemasaran menyebabkan perbedaan harga dimana banyaknya lembaga pemasaran yang terlibat atau rantai pemasarannya semakin panjang, maka semakin besar pula perbedaan harganya sehingga akan 
menyebabkan share harga (bagian harga) yang lebih rendah.

Hal tersebut menarik untuk dikaji sehingga tujuan penelitian ini adalah untuk mengetahui saluran pemasaran dan fungsi pemasaran dari ubi cilembu di Desa Cilembu Kecamatan Pamulihan Kabupaten Sumedang dan besar margin pemasaran, farmer's share, ratio keunggulan dan biaya ubi jalar di Desa Cilembu Kecamatan Pamulihan Kabupaten Sumedang.

\section{METODE PENELITIAN}

Penelitian dilaksanakan pada bulan September-November 2020 di Desa Cilembu Kecamatan Pamulihan Kabupaten Sumedang. Lokasi dipilih dengan secara sengaja (purposive) dengan pertimbangan bahwa lokasi penelitian ini merupakan salah satu sentra ubi jalar yang memiliki ciri khas tersendiri dan berbeda dengan ubi jalar yang dihasilkan dari daerah lain dan memiliki pangsa pasar yang luas.

Penelitian didesain secara kualitatif dengan prosedur deskriptif. Dalam penelitian ini digunakan data primer dan data sekunder. Responden dalam penelitian ini adalah petani ubi cilembu berjumlah 20 orang yang dipilih secara purposive sampling. Menurut Sugiyono
(2010), purposive sampling ialah teknik pengambilan sampel data dengan menggunakan pertimbangan tertentu. Teknik pengambilan data dengan cara snowball sampling terhadap 3 orang pedagang besar dan 3 orang pedagang kecil serta 4 orang tengkulak di Desa Cilembu.

Analisis data dalam penelitian yaitu menggunakan analisis deskriptif yang digunakan untuk menganalisis secara deskriptif pada beberapa aspek, yaitu mengenai mekanisme aliran produk, aliran keuangan, dan aliran informasi pada saluran pemasaran ubi jalar di Desa Cilembu, analisis saluran pemasaran yang digunakan untuk untuk menganalisis saluran pemasaran dilihat dari struktur saluran pemasaran dan fungsi-fungsi lembaga, analisis efisiensi untuk pemasaran perhitungan margin pemasaran, farmer's share, dan rasio keuntungan dan biaya, dan analisis keuntungan dan biaya ubi jalar yang digunakan untuk mengetahui keuntungan dan biaya pada masing-masing pelaku saluran pemasaran.

\section{HASIL DAN PEMBAHASAN}

Desa Cilembu merupakan sebuah desa yang berada di wilayah Kecamatan Pamulihan, Sumedang, Jawa Barat, 
Indonesia. Terletak di wilayah daerah ketinggian di kaki Gunung Kareumbi bagian Barat Laut. Lokasinya sendiri berada di sebelah tenggara pusat Kecamatan Pamulihan dengan jarak pusat kecamatan pamulihan sekitar enam kilometer.

Desa Cilembu berstatus sebagai pedesaan dengan klasifikasi sebagai desa swadaya madya. Secarar topografis Desa Cilembu memiliki bentuk bentang permukaan tanah berupa pegunungan dan secara geografis sendiri wilayah Desa Cilembu berbatasan dengan Desa Cigendel di sebelah utara. Desa Cimarias dan Desa Cinanggerang di sebelah timur. Desa Mekar bakti di sebelah selatan. Desa Haurgombong di sebelah baratnya. Menurut data administrasinya, Desa Cilembu terbagi ke dalam 3 buah dusun, yaitu Dusun I, Dusun II, Dusun III, dengan jumlah Rukun Warga dan Rukun Tetangga masing masing berjumlah 11 RW dan 33 RT.

Desa Cilembu merupakan hamparan pertanian yang bercampur antara ladang, lahan perkebunan, dan persawahan serta kehutanan. Lahan persawahan terletak di bagian barat laut, dimana merupakan bagian paling rendah. Sementara lahan perkebunan dan ladang mendominasi pada bagian tengah yang bercampur dengan pemukiman. Untuk daerah kehutanan sendiri banyak terdapat di wilayah kaki Gunung Kareumbi yang terletak di bagian tenggara Desa Cilembu.

Desa Cilembu memiliki luas wilayah 352 hektar yang terbagi ke dalam beberapa peruntukan seperti lahan pertanian dan permukiman serta peruntukan yang lain. Sementara sisa lahan 135 hektar diperuntukkan sebagai lahan pemukiman dan pekarangan, serta fasilitas umum.

Desa Cilembu memiliki jumlah penduduk 4,919 orang dengan komposisi 2,478 orang berjenis laki-laki dan 2,441 orang berjenis perempuan. Penduduk Desa Cilembu sebagian besar memiliki mata pencaharian utama di bidang pertanian, baik sebagai petani maupun buruh tani. Selain di bidang pertanian, ada juga yang bergerak di bidang jasa dan perdagangan serta transportasi. Di Desa Cilembu terdapat produk pertanian yang menjadi unggulan bagi Kabupaten Sumedang, yaitu ubi cilembu.

Struktur saluran pemasaran atau struktur hubungan anggota saluran pemasaran ubi jalar di Desa Cilembu dianalisis berdasarkan anggota yang membentuk saluran pemasaran dan berperan dari setiap anggota. Lembaga 


\section{ANALISIS SALURAN PEMASARAN UBI JALAR DI DESA CILEMBU \\ KECAMATAN PAMULIHAN KABUPATEN SUMEDANG \\ Rosida Susanti, Dini Rochdiani}

saluran pemasaran dalam hal ini merupakan para pelaku yang terlibat dalam aliran produk, aliran finansial, dan aliran informasi mulai dari petani ubi jalar hingga ke konsumen akhir. Struktur hubungan saluran pemasaran pada komoditas ubi jalar di Desa Cilembu sendiri terdiri atas petani ubi jalar, tengkulak, pedagang besar, pedagang kecil, dan industri pengolahan serta konsumen akhir.

Struktur saluran pemasaran melibatkan lembaga pemasaran dimana di dalamnya melakukan fungsi-fungsi pemasaran sendiri. Secara umum, fungsi pemasaran yang dilaksanakan oleh lembaga pemasaran terdiri atas 3 fungsi, yaitu fungsi pertukaran, fisik, dan fungsi fasilitas. Fungsi pertukaran merupakan kegiatan-kegiatan yang dapat memperlancar perpindahan hak milik dari barang atau jasa yang dipasarkan. Fungsi fisik adalah perlakuan fisik yang perlu dilakukan agar komoditas yang diperlukan konsumen tersedia pada tempat yang diinginkan. Sedangkan fungsi fasilitas meliputi pembiayaan, penanggungan resiko dan informasi pasar.

\section{Margin Pemasaran}

Untuk mengetahui perbedaan pendapatan antara lembaga pemasaran dalam mengalirkan produk hingga ke tangan konsumen, dan juga untuk mengetahui perbedaan harga produk yang diterima konsumen digunakan analisis margin pemasaran. Margin pemasaran sendiri merupakan selisih antara harga jual produk dengan harga beli produk pada setiap lembaga pemasaran.

\section{Famer's Share}

Untuk mengukur besarnya bagian yang diterima petani terhadap harga jual akhir pada sebuah saluran pemasaran digunakan analisis Farmer's Share.

\section{Rasio Keuntungan dan Biaya}

Rasio keuntungan dan biaya digunakan untuk menganalisis keuntungan yang didapatkan dari biaya yang dikeluarkan pada saluran pemasaran. Analisis rasio keuntungan dan biaya didapatkan dengan melihat perbandingan antara besaran biaya dan keuntungan yang didapatkan pada masing-masing lembaga saluran pemasaran.

Terdapat 4 rantai dan 6 lembaga pemasaran ubi jalar di Desa Cilembu, yaitu:

1. Petani - Tengkulak - Pedagang Besar - Pedagang Kecil - Konsumen

2. Petani - Tengkulak - Pedagang Kecil - Konsumen 
3. Petani - Tengkulak - Industri 4. Petani-Tengkulak-Konsumen Pengolahan - Konsumen

Tabel 1. Analisis Nilai Margin Pemasaran, Farmer's Share, dan $R / C$

\begin{tabular}{|c|c|c|c|c|}
\hline \multirow{2}{*}{ Pelaku } & \multicolumn{4}{|c|}{ Saluran } \\
\hline & 1 & 2 & 3 & 4 \\
\hline \multicolumn{5}{|l|}{ Petani } \\
\hline Harga Jual (Rp/Kg) & 5.000 & 5.000 & 5.000 & 5.000 \\
\hline \multicolumn{5}{|l|}{ Tengkulak } \\
\hline Harga Beli (Rp/Kg) & 5.000 & 5.000 & 5.000 & 5.000 \\
\hline Harga Jual (Rp/Kg) & 6.500 & 6.500 & 5.500 & 6.500 \\
\hline Biaya $(\mathrm{Rp} / \mathrm{Kg})$ & 400 & 200 & 200 & 150 \\
\hline Keuntungan (Rp/Kg) & 1.100 & 1.300 & 300 & 1.350 \\
\hline $\operatorname{Margin}(\mathrm{Rp} / \mathrm{Kg})$ & 1.500 & 1.500 & 500 & 1.500 \\
\hline $\mathrm{R} / \mathrm{C}$ & 2,7 & 6,5 & 2,5 & 4 \\
\hline \multicolumn{5}{|l|}{ Pedagang Besar } \\
\hline Harga Beli (Rp/Kg) & 6.500 & - & - & - \\
\hline Harga Jual (Rp/Kg) & 7.500 & - & - & - \\
\hline Biaya $(\mathrm{Rp} / \mathrm{Kg})$ & 200 & - & - & - \\
\hline Keuntungan (Rp/Kg) & 800 & - & - & - \\
\hline $\operatorname{Margin}(\mathrm{Rp} / \mathrm{Kg})$ & 1.000 & - & - & - \\
\hline Rasio R/C & 4 & - & - & - \\
\hline \multicolumn{5}{|l|}{ Pedagang Kecil } \\
\hline Harga Beli (Rp/Kg) & 7.500 & 6.500 & - & - \\
\hline Harga Jual (Rp/Kg) & 11.000 & 10.000 & - & - \\
\hline Biaya $(\mathrm{Rp} / \mathrm{Kg})$ & 750 & 750 & - & - \\
\hline Keuntungan $(\mathrm{Rp} / \mathrm{Kg})$ & 2.750 & 2.750 & - & - \\
\hline $\operatorname{Margin}(\mathrm{Rp} / \mathrm{Kg})$ & 3.500 & 3.500 & - & - \\
\hline $\mathrm{R} / \mathrm{C}$ & 3,6 & 3,6 & - & - \\
\hline \multicolumn{5}{|l|}{ Industri Pengolahan } \\
\hline Harga Beli (Rp/Kg) & - & - & 5.500 & - \\
\hline Harga Jual (Rp/Kg) & - & - & 15.000 & - \\
\hline Biaya $(\mathrm{Rp} / \mathrm{Kg})$ & - & - & 1.000 & - \\
\hline Keuntungan (Rp/Kg) & - & - & 8.500 & - \\
\hline $\operatorname{Margin}(\mathrm{Rp} / \mathrm{Kg})$ & - & - & 9.500 & - \\
\hline $\mathrm{R} / \mathrm{C}$ & - & - & 8,5 & - \\
\hline Konsumen Akhir & 12.000 & 10.000 & 15.000 & 6.500 \\
\hline Total Biaya Pemasaran & 1.350 & 950 & 1.200 & 150 \\
\hline Total Keuntungan & 5.650 & 4.050 & 9.800 & 1.350 \\
\hline Rasio $\mathbf{R} / \mathbf{C}$ & 4,1 & 4,2 & 8,1 & 9 \\
\hline Total Margin & 7.000 & 5.000 & 10.000 & 1.500 \\
\hline Farmer Share (\%) & 41,6 & 50 & 33,3 & 76,9 \\
\hline
\end{tabular}

Lembaga saluran pemasaran pertama ini yang paling banyak diantara ketiga saluran dan melibatkan tengkulak, pedagang besar, pedagang kecil dan konsumen. Petani menjual kepada tengkulak dengan harga Rp 5000/kg, kemudian dijual kembali Rp 6.500/kg.
Pedagang besar menjual kepada pedagang kecil dengan harga $\mathrm{Rp}$ $7.500 / \mathrm{kg}$. Total margin pemasaran pada saluran pertama diperoleh Rp 7.000/kg, dimana selisih margin pemasaran dari setiap saluran pemasaran berbeda-beda yaitu tengkulak ke pedagang besar $\mathrm{Rp}$ 


\section{ANALISIS SALURAN PEMASARAN UBI JALAR DI DESA CILEMBU \\ KECAMATAN PAMULIHAN KABUPATEN SUMEDANG \\ Rosida Susanti, Dini Rochdiani}

$1.500 / \mathrm{kg}$, dari pedagang besar ke pedagang kecil $\mathrm{Rp} 1.000 / \mathrm{kg}$, dan dari pedagang kecil ke konsumen Rp 3.500/kg. Dilihat dari selisih harga beli ubi jalar, maka selisih terbesar berada pada konsumen yang membeli kepada pedagang kecil.

Total margin pemasaran pada saluran kedua yaitu $\mathrm{Rp} \mathrm{5000/kg,} \mathrm{dimana}$ lembaga saluran pemasaran pada saluran kedua ini lebih sedikit dibandingkan dengan yang pertama, yaitu tengkulak sebagai pembeli pertama, dan dijual ke pedagang kecil kemudian dijual kembali kepada konsumen akhri. Harga beli dari tengkulak yaitu Rp 6.500/kg, kemudian dijual kepada konsumen akhir dengan

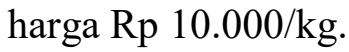

Total margin pemasaran pada saluran ketiga yaitu Rp 10.000/kg. Pada saluran ini, lembaga saluran pemasaran yang terlibat memang sedikit, namun selisih antara harga jual dan harga beli pada industri pengolahan yang lumayan besar membuat margin pemasaran semakin besar juga.

Total margin pemasaran pada saluran keempat yaitu Rp 1.500/kg. Saluran keempat ini merupakan saluran dengan lembaga saluran pemasaran yang sedikit dimana hanya melibatkan petani, tengkulak, dan konsumen akhir saja.
Konsumen akhir membeli ubi jalar kepada tengkulak dengan harga $\mathrm{Rp}$ $6.500 / \mathrm{kg}$.

Margin pemasaran terbesar berada pada saluran ketiga dengan total margin $\mathrm{Rp}$ 10.000/kg, karena besarnya selisih antara harga jual petani dan harga jual industri pengolahan, sedangkan pada saluran keempat yaitu yang terkecil dengan total margin pemasaran Rp 1.500. Hal ini dikarenakan pada saluran keempat hanya melibatkan sedikit lembaga saluran pemasaran, yaitu hanya tengkulak. Soekartawi (2002) menyatakan bahwa semakin pendek saluran pemasaran, maka semakin kecil pula margin pemasarannya sehingga dapat menguntungkan produsen.

Nilai farmer's share pada saluran pemasaran pertama, kedua, dan keempat adalah $\geq 40 \%$ dimana pada saluran pertama yaitu $41,6 \%$, saluran kedua $50 \%$, dan saluran keempat $76,9 \%$, artinya nilai farmer's share pada ketiga saluran pemasaran tersebut tergolong efisien. Nilai farmer's share pada saluran pemasaran keempat merupakan yang paling besar di antara keempat saluran pemasaran. Hal tersebut disebabkan karena melibatkan sedikit lembaga pemasaran dibandingkan pada saluran pertama dan kedua. Semakin kecil nilai farmer's share yang diterima petani 
memperlihatkan bahwa semakin banyak lembaga pemasaran yang terlibat. Begitu pun sebaliknya, semakin besar nilai farmer's share yang diterima petani, maka menandakan semakin sedikit Lembaga pemasaran yang terlibat (Limbong dan Sitorus, 1992).

Nilai farmer's share yang diterima petani pada saluran ketiga yaitu 33,3\%. Nilai farmer's share pada saluran ketiga kurang dari $40 \%$ yang berarti bahwa pada saluran ini belum efisien.

$\mathrm{R} / \mathrm{C}$ tertinggi diperoleh saluran keempat yakni $\quad 9,0$ sedangkan $\mathrm{R} / \mathrm{C}$ terendah diperoleh oleh saluran pertama yaitu 3,4. R/C antara saluran pertama $(4,1)$ dan kedua $(4,2)$ tidak berbeda jauh, yang memperlihatkan juga keuntungan yang tidak berbeda jauh. Walaupun keuntungan yang tidak berbeda jauh antara saluran pertama (5650) dan kedua (4050), namun biaya yang dikeluarkan saluran kedua (950) lebih sedikit dibandingkan saluran pertama (1350). Menurut Soekartawi (2006), jika R/C > 1, maka usaha yang dijalankan mengalami keuntungan atau layak untuk dikembangkan. Sebaliknya, jika R/C $<1$, maka usaha tersebut mengalami kerugian atau tidak layak untuk dikembangkan. Apabila $\mathrm{R} / \mathrm{C}=1$, maka usaha tersebut berada pada titik impas. Setiap lembaga saluran pemasaran di setiap saluran, memiliki nilai $\mathrm{R} / \mathrm{C}$ diatas 1 yang artinya usaha tersebut dikatakan mengalami keuntungan.

\section{KESIMPULAN DAN SARAN \\ Kesimpulan}

Berdasarkan pembahasan data hasil penelitian yang telah dilakukan, dapat disimpulkan adalah dalam saluran pemasaran ubi jalar Desa Cilembu terdapat 6 lembaga pemasaran yang berperan aktif, yaitu petani, tengkulak, pedangang besar, pedagang kecil, industri pengelolaan, dan konsumen akhir. Fungsi pemasaran yang dilakukan oleh petani adalah fungsi pertukaran dan fungsi fasilitas. Sedangkan fungsi pemasaran yang dilakukan oleh tengkulak, pedagang besar, pedagang kecil, dan industri pengolahan adalah fungsi pertukaran, fungsi fisik dan fungsi fasilitas. Pada saluran pemasaran pertama besar total margin pemasaran adalah $\mathrm{Rp} 7.000 / \mathrm{kg}$ dengan total biaya pemasaran sebesar Rp $1.350 / \mathrm{kg}$ sehingga total keuntungan Rp. $5.650 / \mathrm{kg}$ dengan rasio keuntungan dan biaya sebesar 4,1 dan farmer's share 41,6\%. Pada saluran pemasaran kedua besar total margin pemasaran adalah $\mathrm{Rp}$ $5.000 / \mathrm{kg}$ dengan total biaya pemasaran sebesar Rp 950/kg sehingga total 
keuntungan $\mathrm{Rp} 4.050 / \mathrm{kg}$ dengan rasio keuntungan biaya sebesar 4,2 dan farmer's share sebesar 50\%. Pada saluran ketiga besar total margin pemasaran adalah Rp 10.000/kg dengan total biaya pemasaran sebesar Rp 1.200/kg sehingga total keuntungan $\mathrm{Rp} 9.800 / \mathrm{kg}$ dengan rasio keuntungan dan biaya sebesar 8,1 dan farmer's share 33,3\%. Pada saluran keempat besar total margin pemasaran adalah $\mathrm{Rp} 1.500 / \mathrm{kg}$ dengan total biaya pemasaran sebesar Rp 150/kg sehingga total keuntungan $\mathrm{Rp} 1.350 / \mathrm{kg}$ dengan rasio keuntungan, dan biaya sebesar 9 dan farmer's share 76,9\%.

\section{Saran}

Berdasarkan hasil penelitian yang telah disimpulkan, meningkatkan posisi tawarnya, petani dapat lebih mengaktifkan kembali kelompok tani yang sudah terbentuk, karena kelompok tani dapat membantu serta mendukung petani dalam kegiatan usahataninya dari proses budidaya sampai ke pemasaran. Saluran pemasaran pada saluran ketiga yang belum efisien, maka lembaga pemasaran bisa lebih bekerjasama dan berkomunikasi dengan baik agar menciptakan saluran pemasaran yang efisien. Selain itu, dapat juga dibantu dengan program yang dapat memberi keuntungan lebih kepada petani seperti menjadikan wisata terhadap areal lahanlahan di Desa Cilembu, ataupun dengan melakukan nilai tambah terhadap ubi jalar untuk petani agar mengoptimalkan farmer's share dan memperkecil margin pemasarannya.

\section{DAFTAR PUSTAKA}

Prasetyana, R. 2010. Analisis Preferensi Konsumen Terhadap Ubi Jalar (Ipomoea batatas L.) Di Kota Surakarta. universitas sebelas maret.

Zuraida N, dan Y. Supriati . 2005. Usahatani Ubi Jalar Sebagai Bahan Pangan Alternatif dan Diversifikasi Sumber Karbohidrat. Buletin agrobio Vol 4 No. 1: 13-23.

Suismono, 2001. Teknologi pembuatan tepung dan pati ubi-ubian untuk menunjang ketahanan pangan. Di dalam: Majalah Pangan Vol. X No. 37: 37-49. Puslitbang Bulog, Jakarta.

Hidayat, A., S.A. Andayani., dan J. Sulaksana. Analisis Rantai Pasok Jagung (Studi Kasus Pada Rantai Pasok Jagung Hibrida ( Zea Mays ) Di Kelurahan Cicurug Kecamatan Majalengka Kabupaten Majalengka). Jurnal ilmu pertanian dan peternakan. vol 5 no 1.

Kotler, P. $2006 . \quad$ Manajemen

Pemasaran (Analisis, Perencanaan, dan Pengendalian), Terjemahan Drs. Jaka Wasana MSM, Institut dan Pembinaan Manajemen, Jilid I, Edisi Kelima, Erlangga, Cetakan Ketujuh, Jakarta.

Sugiyono. (2010). Metode Penelitian Kuantitatif Kualitatif dan R\&D. Bandung : Alfabeta. 
Limbong dan Sitorus. 1992. Pengantar Tataniaga Pertanian. Institut Pertanian Bogor. Bogor. 